\title{
O GeoGebra e a suas contribuições para o ensino de geometria espacial na perspectiva dos professores de matemática
}

\section{GeoGebra and its contributions to the teaching of spatial geometry from the perspective of mathematics teachers}

\author{
Jane Maria de França Nolasco ${ }^{1}$, José Ronaldo Melo*
}

\begin{abstract}
RESUMO
O uso de novas tecnologias no ensino de matemática vem se constituído cada vez mais como formas alternativas ao ensino tradicional. Além disso, uma quantidade considerável de softwares educacionais estão atualmente sendo propostos como recursos metodológicos, com a finalidade de potencializar o ensino e a aprendizagem matemática. Neste sentido, este produto educacional tem como objetivo auxiliar o professor de matemática na construção de conceitos sobre geometria espacial, procurando oferecer ao aluno uma aprendizagem significativa e oportunizando uma discussão mediada por aspectos teóricos metodológicos presentes na literatura e em pesquisas que abordam uso do GeoGebra para o ensino de geometria. Os dados foram produzidos a partir de um diagnóstico e de entrevistas semiestruturadas, apresentando como resultado uma proposta de ensino sobre geometria espacial para o Ensino Fundamental II, produzida durante o período de ensino remoto, com auxílio do software GeoGebra, que poderá contribuir para ampliação de teorias e uso de tecnologias, proporcionando recursos alternativos ao ensino de Matemática.
\end{abstract}

Palavras-chave: Ensino e aprendizagem; Geometria Espacial; Software GeoGebra.

\section{ABSTRACT}

The use of new technologies in mathematics teaching has been increasingly constituted as alternative ways to traditional teaching. In addition, a considerable amount of educational software has been proposed as methodological resources, in order to enhance the teaching and learning of mathematics. In this sense, this educational product aims to help the mathematics teacher in the construction of concepts about spatial geometry, seeking to offer the student a significant learning, offering a discussion mediated by theoretical and methodological aspects present in the literature and in research that approach the use of GeoGebra for the teaching of geometry. The data were produced from a diagnosis and semi-structured interviews, presenting as a result a teaching proposal on spatial geometry for Elementary School II, produced during the remote teaching period, with the help of GeoGebra software, which may contribute to the expansion of theories and use of technologies, providing alternative resources for teaching Mathematics.

Keywords: Teaching and learning; Spatial Geometry; GeoGebra Software

\footnotetext{
${ }^{1}$ Secretária de Estado da Educação do Estado do Acre

${ }^{2}$ Universidade Federal do Acre*E-mail: ronaldo.ufac@gmail.com correspondente@autor.com.
} 


\section{INTRODUÇÃO}

A busca por formas diversificadas para melhorar o ensino e potencializar a aprendizagem, é um grande desafio para os professores de matemática, pois hoje, por meio de várias tecnologias, podemos buscar melhorias na qualidade de ensino proporcionando aulas de matemática de forma mais motivadoras, de maneira que o aluno possa alcançar uma aprendizagem significativa, através de um processo de interação que segundo Moreira e outros (1997) acontece "entre conhecimentos prévios e conhecimentos novos de maneira não literal e não arbitrária, para o qual novos conhecimentos adquiram significado para o sujeito e os conhecimentos prévios adquirem novos significados ou maior estabilidade cognitiva."

Os projetos pedagógicos das escolas, geralmente, estabelecem seus objetivos, suas metas e concepções de ensino e aprendizagem que consideram válida, determina, de certo modo, a utilização dos meios tecnológicos mais adequados ao alcance dessas expectativas. Verifica-se que para a implantação de um programa educacional que utilize tecnologias na sala de aula se faz necessário investimento na infraestrutura escolar; na capacitação dos docentes e corpo administrativo, bem como orientação aos discentes. A utilização do computador, Smartphone e Tabletes, por exemplo, com o auxílio de softwares educacionais poderá potencializar o ensino e a aprendizagem da matemática.

Por outro lado, a Geometria é uma área do conhecimento utilizada de forma prática desde o tempo dos antigos egípcios, principalmente para medir terrenos e realizar construções. Em particular, a Geometria Espacial é um tema da Matemática com muitas aplicações práticas. Apesar disto, os estudantes geralmente apresentam muitas dificuldades para compreendê-la, partindo daí a necessidade de se trabalhar de forma criativa e prática, incentivando a aprendizagem sem, no entanto, renunciar às conceituações inerentes ao assunto.

Nesse sentindo, a pesquisa que originou esse produto educacional procurou responder a seguinte questão: “como os (as) professores (as) de matemática, em sua prática docente, utilizam o software Geogebra no planejamento e desenvolvimento de atividades sobre geometria espacial, no ensino fundamental II e de que maneira o uso desse software está favorecendo uma aprendizagem significativa dos alunos em sala de aula". 


\section{CONTRIBUIÇÕES DO GEOGEBRA PARA O ENSINO DE GEOMETRIA}

Atualmente o professor de Matemática pode dispor de um conjunto de softwares educacionais para auxílio ao ensino. O GeoGebra, por exemplo, vem sendo bastante utilizado, oferecendo recursos diversos para planejamento e condução do ensino em sala de aula. Esse software foi objeto de estudo da tese de doutorado do austríaco Markus Hohenwarter, em 2001, na Universidade de Salzburgo, que o criou e desenvolveu visando todas as modalidades de ensino (do Fundamental ao Ensino Superior) com o objetivo de obter um instrumento adequado ao ensino da Matemática, permitindo o estudo de Álgebra, Geometria, Planilha de Cálculo, Gráficos, Probabilidade, Estatística e Cálculo em um único ambiente. Este software permite a criação de figuras em $2 \mathrm{D}$ e $3 \mathrm{D}$. $\mathrm{O}$ GeoGebra é um sistema de geometria dinâmica que permite a realização de diferentes atividades, entre elas, a construção de pontos, segmentos de reta, retas paralelas e perpendiculares, construção de gráficos de funções, construção de figuras geométricas, permite ainda calcular o ponto médio dos segmentos, a área, o perímetro das figuras, medir ângulos, entre outras.

Autores como Borba, Scucuglia e Gadanidis (2016), Andrade (2015), Abar e Cotic (2014), Girardo (2012), Pereira (2012), Fanti (2010), entre outros, concordam que o uso do software GeoGebra pode contribuir de forma significativa para enriquecer a prática docente. Fanti (2010, p. 1), argumenta que,

O GeoGebra é um software livre e pode ser usado facilmente como uma
importante ferramenta para despertar o interesse pela busca do conhecimento
matemático principalmente com alunos dos ensinos fundamental e médio.
Possibilita trabalhar de forma dinâmica em todos os níveis da educação básica
permitindo a abordagem de diversos conteúdos especialmente os relacionados
ao estudo da geometria e funções.

Assim, o uso do GeoGebra possibilita uma mobilidade de explorações acerca de figuras e objetos tridimensionais, bem como de suas respectivas representações. Segundo Borba e Penteado (2017, p. 37), propostas pedagógicas desenvolvidas com softwares gráficos, por exemplo, “[...], permitem que o aluno experimente bastante, de modo semelhante ao que faz em aulas experimentais de biologia ou de física”. Também, ao interagir com o software, além de perceber os conceitos matemáticos envolvidos, o aluno terá a oportunidade de realizar construções que se tornariam impossíveis de serem executadas, de forma tão precisa, rápida e dinâmica, com lápis e papel. Para Pereira (2012, p. 32), "as características do GeoGebra potencializam a constituição de cenários para investigação, nos quais o aluno é capaz de experimentar situações em um processo 
dinâmico". Assim, a visualização dos objetos construídos proporcionada pelo software pode favorecer a construção de um ambiente mais propício para a aprendizagem matemática e se tornar um importante recurso no processo de ensino.

Através de rotações no objeto construído, por exemplo, podem-se explorar situações virtuais que acionam habilidades de visualização muito similares àquelas decorrentes da manipulação de objetos 3D no espaço real. Nesse sentido, as propriedades dinâmicas da versão 3D do GeoGebra para desktop ou smartphones pode ser usada como uma ferramenta valiosa nas construções dos objetos tridimensionais abordados no estudo da Geometria Espacial. Diversos sólidos, superfícies e curvas tridimensionais podem ser construídas sem dificuldade com essa versão do GeoGebra, assim como ocorre com o cálculo de seus comprimentos, áreas, volumes e interseções (ANDRADE, 2015, p. 36).

Destacamos que explorar os aspectos visuais do GeoGebra com atividades pedagógicas que ofereçam meios para a investigação matemática e experimentação com tecnologias, assume uma dimensão heurística, sendo apropriada aos cenários de ensino e aprendizagem de Matemática (BORBA; SCUCUGLIA; GADANIDIS, 2016). Dessa forma, o processo de formação de imagens é protagonista na produção de sentidos e na aprendizagem dos conteúdos geométricos. Conforme esses autores,

O GeoGebra, que mantém possível o estudo de conteúdos de forma mais próxima ao que era feito com lápis e papel, transforma também as possibilidades de experimentação, de visualização e de heurística dos humanos envolvidos nesse coletivo que aprende (BORBA; SCUCUGLIA; GADANIDIS, 2016, p. 73).

Portanto, as possibilidades que o GeoGebra 3D oferece para explorar e investigar os sólidos geométricos podem modificar o tipo de atividades que são propostas em sala de aula, bem como transformar a natureza do conhecimento matemático. Este ambiente possibilita que os alunos visualizem os objetos construídos de maneira diferente do que estão habituados a observarem nos livros didáticos. Ao explorar um objeto construído no GeoGebra 3D, determinada representação aparece como uma das posições possíveis que o objeto pode assumir, e isto proporciona significado e movimento às imagens mentais que são criadas pelo aluno. Além disso, os alunos podem interagir com o objeto construído e assim formar imagens mentais mais significativas.

\section{ASPECTOS METODOLOGICOS}

No desenvolvimento da nossa prática docente, constatou-se como apontado por vários outros pesquisadores citados, que as dificuldades apresentadas pelos alunos na resolução de problemas envolvendo Geometria Espacial se iniciam com as dificuldades 
de aprendizagem dos conceitos de Geometria Plana. Essas dificuldades parecem se intensificar quando se começa a trabalhar com objetos tridimensionais, a partir de representações do plano, especialmente em problemas clássicos que envolvam áreas, volumes, planificações e relações entre elementos (vértices, faces e arestas) dos sólidos estudados. Segundo Gravina (1996, p. 2), "a construção de objetos geométricos raramente é abordada; dificilmente encontramos no livro escolar a instrução "construa", e, no entanto, esta é uma das atividades que leva o aluno ao domínio de conceitos geométricos". Neste sentido, este estudo teve por objetivo compreender como o uso adequado do software Geogebra pode auxiliar o professor de matemática no planejamento e na produção de atividades visando uma aprendizagem significativa sobre Geometria Espacial.

Para isso realizou-se um diagnóstico junto aos professores do Ensino Fundamental II, identificando os (as) professores (as) que planejam e desenvolvem suas aulas com o auxílio de softwares educacionais. Depois, entre os professores (as) identificados como usuário de softwares educacionais, particularmente em relação ao GeoGebra, realizou-se uma entrevista semiestruturada, na qual os participantes tiveram a oportunidade de responder questões e refletir sobre o desenvolvimento e inclusão dessa tecnologia, visando uma aprendizagem mais eficaz dos alunos em sala de aula.

Neste trabalho, procuramos identificar alguns dos principais fatores que dificultam o ensino dos conteúdos relacionados com a Geometria Espacial no Ensino Fundamental, particularmente nos anos finais $\left(6^{\circ}\right.$ ao $9^{\circ}$ ano). Voltamos nossa atenção principalmente para as atividades que podem ser desenvolvidas pelos professores na tentativa de minimizar os problemas de aprendizagem da Geometria, procurando desenvolver no estudante uma melhor percepção espacial, de forma que ele possa resolver situações-problemas.

Tomamos como referência, portanto, uma abordagem qualitativa, que, segundo Bogdan e Biklem, citados por Lüdke e André (1986, p. 22), “envolve a obtenção de dados descritivos, obtidos no contato direto do pesquisador com a situação estudada, enfatiza mais o processo do que o produto e se preocupa em retratar a perspectiva dos participantes", considerando aspectos singulares sobre como as concepções, as práticas pedagógicas e curriculares são vivenciadas por cada sujeito.

O primeiro instrumento utilizado para a realização dessa pesquisa foi um questionário com perguntas voltadas para os professores de matemática do Ensino 
Fundamental II, com o intuito de obter informações relacionadas à utilização algum tipo de softwares educacionais em sala de aula.

A partir das informações obtidas foi diagnosticado que parte significativa desses professores utilizavam, predominantemente o software GeoGebra, quando do planejamento e execução de suas aulas, sobretudo para o desenvolvimento de conteúdos de geometria, especialmente a geometria espacial.

\title{
PROPOSIÇÃO PARA O ENSINO DE GEOMETRIA ESPACIAL
}

Apresentaremos nesta secção as reflexões dos professores quando da utilização do GeoGebra, na espectativa de que essas informações possa contrbuir para uma formalização de proposta de ensino para geometria espacial com auxilio do GoeGebra.

\section{Vantagens da utilização da GeoGebra}

Indagamos como essa ferramenta pode favorecer a aprendizagem da geometria espacial, facilitando a prática docente na Matemática? A partir das respostas dos sujeitos, percebemos que uma das vantagens na utilização do software educacional GeoGebra em sala de aula é o processo de mobilização da curiosidade dos jovens aliada à criatividade dos professores como favoráveis à utilização da tecnologia para facilitar o aprendizado, verificada na fala do Professor B, que ressalta:

\begin{abstract}
A gente percebe que a partir do momento que eles utilizam o GeoGebra, eles aprendem da maneira mais dinâmica né, eles exploram a criatividade deles, olha tio eu consegui construir um cubo, uma pirâmide, minha pirâmide eu consigo fazer com o que ela fique oblíqua, reta, eu consigo mudar a base da pirâmide, ela pode ser uma base quadrada, pentagonal, hexagonal e tudo isso eu posso fazer manuseando com o dedo, com o mouse, então a gente percebe que a partir do momento que o GeoGebra é implementado no ensino da matemática no ensino fundamental II, que é onde de fato começa a explorar esse conhecimento da geometria espacial, o ensino vai ficando mais agradável e os alunos vão aprendendo mais de maneira mais autônoma e mais criativa, então eu acredito que isso é uma questão interessante de ser explorado, é uma questão que vai te trazer bastante resultado significativos e que vai mostrar a importância do uso do GeoGebra pra de fato tornar a matemática mais prazerosa de se aprender e mais significativa para os alunos (Professor B).
\end{abstract}

Para os Professores B e C, a mobilização dos alunos em busca de aprendizagens significativas vai além do uso específico do GeoGebra, pois, propostas de ensino que levam em consideração o uso de tecnologias da comunicação e da informação TICs são bem aceitas em sala de aula:

Acredito que quando se trata do uso de tecnologias a postura mais admirada pelos alunos de fato é a criatividade. Um professor criativo possui capacidade de trabalhar em grupo, de improvisar, de adequação à metodologia da escola, de 
administrar o tempo e cumprir cronogramas, de fazer inovações e de buscar novos percursos. Uma aula criativa pode incluir canais de comunicações, sensações, experiências e outros campos variados que aumentem o impacto da informação sobre o cérebro (Professor B).

Partindo da curiosidade que existem em nossos jovens atuais, por exemplo a grande demanda do uso de recurso tecnológico seja ele computacional seja ele material lúdicos quando a gente está falando aqui de recursos tecnológicos não quer dizer somente a máquina o computador, mas são todos aqueles elementos que mobilizam o aluno a partir do concreto para o conceitual e aí quando o aluno tem essa vivência do conteúdo concreto para o conceitual a gente tem um dinamismo maior dentro do processo de ensino, o aluno ele se sente fazendo parte desse todo, diferente de quando você tem um aluno sendo trabalhado o inverso, por exemplo as salas de aulas antigas (Professor $\mathbf{C}$ ).

Essas vantagens são confirmadas através das pesquisas expostas no início deste texto, sobretudo nos trabalhos de Pavanello (1989); Kenski (2003) e Gravina (2015). As afirmações do Professor D exposta a seguir tem muitas semelhanças com o pensamento dessas autoras. Para esse professor a educação:

(...) enfrenta diversos desafios quanto ao ensino de matemática. Com frequência encontramos alunos que manifestam aversão à disciplina, e nas escolas encontramos alunos desinteressados e desmotivados em relação à matemática, levando a uma sociedade com dificuldades de realização de atividades simples do cotidiano e profissional. Diante dessa problemática vemos o uso das ferramentas tecnológicas como recurso motivador no ensino de matemática (Professor D).

Assim, podemos inferir que toda e qualquer tecnologia que possui potencialidades e características de comunicação e manipulação de informações parecem "adequar-se perfeitamente às atividades ligadas à educação, na medida em que o ato de ensinar/aprender consiste, sobretudo, em uma relação de comunicação por excelência" (TEIXEIRA e BRANDÃO, 2003), isso também fica evidente na fala do Professor B, quando menciona o dinamismo da aula, facilitando a prática do ensino

Hoje em dia além do software propriamente dito existe uma plataforma do GeoGebra onde o professor pode encontrar uma gama de recursos já prontos e que pode ser utilizado tanto pelo professor como pelo aluno, o acesso é livre, só basta criar uma conta, uma conta bem simples não tem custo nenhum e isso faz com o que surja autonomia tanto da parte do professor como do aluno para poder aprender a matemática, acredito que o professor além de ensinar matemática né , a gente vive, nos professores vivemos em constante aprendizado, então a partir do momento que passamos a usar recursos tecnológicos, passamos a aplicar esses recursos nas nossas aulas os alunos vão passar a ter um olhar diferente né , então com esse olhar diferente a gente observa que isso torna mais proveitoso , mais prático para se aprender matemática (Professor B).

O Professor B também enfatiza o ganho de tempo que esse recurso traz para o ensino da matemática:

As vantagens eu observo que o GeoGebra ele passou a dinamizar o meu tempo, eu levava tempo para desenhar sólidos geométricos por exemplos, hoje em dia eu posso levar os sólidos já prontos ou semiprontos para sala de aula, faz com que dinamize meu tempo, além disso o GeoGebra faz com que minhas aulas 
sejam mais dinâmicas ou seja é trazendo recursos tecnológicos para dinamizar a aula de forma, trazer uma aula mais animada, mais atrativa. Os alunos podem acompanhar do celular, podem utilizar o GeoGebra do celular, então tudo que eu faço de construção projetando no quadro, eles podem fazer pelo celular ou pelo notebook, então é um recurso que ele tem, trago assim praticidade na minha prática docente (Professor B).

Dessa forma, as estratégias metodológicas que utilizem tecnologias, como o GeoGebra, trazem para a sala de aula uma tarefa de criação de experiências que fazem o conhecimento geométrico acontecer na evolução de um nível básico da intuição e das conjecturas no sentido argumentado por (DUVAL, 2012).

E ao ensinar matemática com a utilização do GeoGebra, um dos entrevistados explica que o uso deste software facilita o entendimento e torna aquilo que era abstrato visível aos olhos tanto do professor como do aluno, facilitando assim o aprendizado e ajudando na resolução de determinados problemas de matemática que envolve vários conteúdos.

Eu acho que principalmente na parte prática do conteúdo, por que você visualiza algo espacial no plano é muito abstrato né, você olhar algo que é espacial numa folha de papel que é plana, então nessa parte prática principalmente envolvendo a tecnologia é a parte que você vai consegui envolver teu aluno, pra ele compreender melhor o conteúdo, porquê os conceitos a gente tem que dá, a gente não pode fugir do conceito do livro didático ,mais na hora prática eu acho que o GeoGebra facilita muito essa compreensão da visualização espacial do objeto (Professor B).

O discurso do Professor B em defesa do uso de tecnologias modernas no ensino de matemática para diversos conteúdos de ensino de matemática parece ir além da utilização do GeoGebra por diversas razões colaboradas pela literatura, entre elas nas pesquisas de Borba e Penteado (2017) ao analisar o papel das tecnologias digitais, assim como possiblidades e transformações que elas provocam no contexto da educação e, em particular, da educação matemática:

No ano de 2019 , estava com turmas do $7^{\circ}$ Ano do Ensino Fundamental II e
sabemos que nesse ano encontrasse a temática de Equação do $1^{\circ}$ Grau nos
documentos oficiais (currículo). Pensando nas dificuldades que os alunos
encontram nesse período da álgebra planejei para a sequência didática para
abordar a Equação do $1^{\circ}$ Grau a partir de um jogo: Sr X. Esse jogo está na
plataforma da Play Store e pode ser usado em qualquer android ou iOS. A partir
do jogo pude fazer a introdução da temática com o jogo e construindo um
campeonato dentro das turmas. Como o jogo aborda o balanceamento em suas
etapas pude fazer a contextualização para trabalhar o balanceamento dentro da
Equação do $1^{\circ}$ Grau. Os resultados apresentados foram positivos, porque os
alunos ficaram envolvidos em todos os sentidos e compreenderam a temática
abordada com maior facilidade (Professor B).

A prática de sala de aula dos professores entrevistados permeadas pelo uso de tecnologias modernas, sobretudo o GeoGebra está de conformidades também com as 
prescrições da Base Nacional Comum Curricular (BNCC), com destaque para $5^{\text {a }}$ Competência Geral, indicando que os alunos precisam:

\begin{abstract}
Compreender, utilizar e criar tecnologias digitais de informação e comunicação de forma crítica, significativa, reflexiva e ética nas diversas práticas sociais (incluindo as escolares) para se comunicar, acessar e disseminar informações, produzir conhecimentos, resolver problemas e exercer protagonismo e autoria na vida pessoal e coletiva (BRASIL, 2018).
\end{abstract}

Outra percepção importante percebida com a fala dos sujeitos desta pesquisa, demonstra que eles conseguem relacionar benefícios de se utilizar o GeoGebra e outros softwares, previstos no currículo da BNCC, para apoiar o ensino da matemática:

\begin{abstract}
Como a matemática é um componente curricular fluido, dinâmico e de fácil inter-relação com outras ciências. Então, contextualizar a matemática é necessária por dois motivos relevantes dentro do ensino de matemática. Primeiro, pensar de como a matemática chega aos alunos e, segundo, de como a matemática é apresentada nos documentos oficiais que regem a rede pública de ensino. Os documentos oficiais, como a BNCC e OCs, já trazem em seu texto orientações para que a matemática seja apresentada aos alunos de forma contextualizar e trazendo uma inversão metodológica. Assim, a matemática fica próxima ao contexto social do indivíduo dentro do processo de ensino e aprendizagem.
\end{abstract}

Com um olhar especial também sobre os PCNs (2006), vemos na fala do Professor $\mathbf{C}$ o uso da ferramenta como cumprimento das competências da Matemática, quando determina como a "Investigação e compreensão, competência marcada pela capacidade de enfrentamento e resolução de situações-problema, utilização dos conceitos e procedimentos peculiares do fazer e pensar das ciências" (BRASIL, 2002, p. 113).

Referindo-se às possibilidades no uso das tecnologias, um dos participante argumentou que:

O processo de ensino e aprendizagem, atualmente, requer esforços para formar um cidadão para a vida. Assim, destacamos o apoio das novas tecnologias como forma de exploração para atender as necessidades dos alunos. Sendo assim, é necessário refletir quais os efeitos do uso do Software como ferramenta tecnológica na resolução de problema no ensino de matemática (Professor C).

\title{
Vantagens para uma aprendizagem significativa do aluno
}

O caráter pedagógico das mídias digitais, segundo Kensky (2007), se comprova nos fatos de que as TICs oferecem uma variedade de informações, dados, ícones, mapas, movimentos etc. Contudo, é preciso enfatizar que a atuação do professor neste processo pedagógico é imprescindível. Cabe ao professor o papel principal: ajudar o aluno a interpretar esses dados, selecionando, relacionando, organizando e contextualizando.

Destacamos, assim, que explorar os aspectos visuais do GeoGebra com atividades pedagógicas que ofereçam meios para a investigação matemática e experimentação com 
tecnologias, assume uma dimensão heurística, sendo apropriada aos cenários de ensino e aprendizagem de Matemática (BORBA; SCUCUGLIA; GADANIDIS, 2016).

Dessa forma, o processo de formação de imagens é protagonista na produção de sentidos e na aprendizagem dos conteúdos geométricos. Conforme esses autores,

O GeoGebra, que mantém possível o estudo de conteúdos de forma mais próxima ao que era feito com lápis e papel, transforma também as possibilidades de experimentação, de visualização e de heurística dos humanos envolvidos nesse coletivo que aprende (BORBA; SCUCUGLIA; GADANIDIS, 2016, p. 73)

Essa percepção também é compartilhada pelos docentes, que veem os resultados na prática da sala de aula, "É essencial para que as aulas saiam da rotina, faz com que, o aluno tenha mais interesse, ou seja, se torne protagonista do processo de ensino e aprendizado no ensino de matemática" (Professor D).

Outra vantagem percebida na pesquisa diz respeito à atenção e participação nas aulas: "Em relação as atitudes dos alunos no desenvolvimento de aula com o uso de software educacional apresentam maior motivação e em envolvimento durante as atividades propostas" (Professor D).

A utilização do software para melhorar a compreensão da geometria foi bastante citada entre os docentes, sobretudo, porque esse instrumento permite diversificar a apresentação de conceitos, colaborando como argumenta Durval (2012) com possibilidades de estratégias para ensinar a matemática de outra forma, permitindo entrar no modo matemático de pensar através dos registros de representações semióticas. Em relação a esses aspectos o Professor A argumenta que antes do uso do GeoGebra seus alunos apresentavam diversas dificuldades.

\footnotetext{
Os meninos tiveram dificuldades em visualizar aquela figura que estava no livro no 3D, então principalmente quando dei a diferença de prisma e pirâmides e dei poliedros, também para eles né, eles tinham essa dificuldades de identificar, faces, arestas, vértices também, e eles tinham dificuldades também principalmente quando tinha alguma questão que tinha planificação, eles não conseguiam visualizar aquela planificação fechada na figura espacial, então a minha principal dificuldade era essa, principalmente quando eu trabalhava poliedros com eles e para ele caracterizar arestas, faces e vértices e principalmente quando eles estavam na planificação, quando eles tinham os objetos em mão, quer dizer, as vezes eu trabalhava também com o manipulado ficava mais fácil, mais quando era uma atividade que tinha planificação e o objeto não dava para eles em 3D então ele tinham muitas dificuldades em analisar (Professor A).
}

Já o Professor $\mathbf{C}$ informa que através do GeoGebra consegue-se "observar a diferença entre uma figura plana e espacial; observar o comportamento de diferentes tipos 
de gráficos; compreender a localização de coordenadas no plano cartesiano" (Professor C) e argumenta que:

Os alunos percebem o quanto é importante aprender geometria com o auxílio de software que dão uma melhor visão das composições geométricas estudadas. Os alunos, de modo geral, começam a perceber como a ideia de planificações e construção de figuras planas e sólidos geométricos são interessantes e fáceis de aprender" (Professor C).

Foi possível perceber, ainda, a partir dos depoimentos dos professore, como as TICs se tornaram, na visão deles, indispensáveis para o planejamento e ensino de Matemática em sala de aula, colaborando com aspectos positivos presentes nas pesquisas realizadas por Moreira e outros (1997) que discutem a relação entre conhecimentos prévios e conhecimentos novos com aquisição de novos significados para o sujeito.

\begin{abstract}
A tecnologia na matemática principalmente no uso de softwares e de aplicativos de celular não oferece apenas maneiras mais dinâmicas para trabalhar os conteúdos. Ela promove novas formas de aprender, permitindo aos alunos assumirem uma postura muito mais crítica e atuante no processo de desenvolvimento. Portanto, entendemos que hoje não dar mais para não utilizar todos os recursos que a tecnologia nos oferece em nossa prática docente (Professor B).
\end{abstract}

Isso colabora também com o entendimento de Gravina (2015) sobre o ensino de geometria desenvolvido por meio de abordagens tecnológicas, como o uso do GeoGebra, desde que os conteúdos estejam organizados de forma diferente, inovadora, no sentido de se explorar os benefícios do software, no sentido de "desenvolver a competência investigativa no aluno por meio dos vários experimentos e experimentações que se pode acessar numa tela interativa" (GRAVINA, 2015, p. 251). Neste sentido o professor A argumenta que:

\begin{abstract}
A tecnologia permite que o aluno se torne protagonista do processo de ensinoaprendizagem, torna as aulas mais atrativas, além de aproximar o ensino escolar do mundo tecnológico que eles vivenciam no dia a dia. (...) Antes trabalhava estes conteúdos apenas no caderno e quadro, porém, percebi que muitos não compreendiam o comportamento dos gráficos e as principais características das formas geométricas. Após o uso dos softwares, percebi um melhor aprendizado pelos alunos, além de tornar as atividades mais prazerosas (Professor A).
\end{abstract}

Na perspectiva desse professor "a tecnologia na matemática principalmente no uso de softwares e de aplicativos de celular não oferece apenas maneiras mais dinâmicas para trabalhar os conteúdos". Promove na visão dele "novas formas de aprender, permitindo aos alunos assumirem uma postura muito mais crítica e atuante no processo de desenvolvimento. Portanto, entendemos que hoje não dar mais para não utilizar todos os recursos que a tecnologia nos oferece em nossa prática docente" (Professor A). 
De acordo com Vygotsky (1989), essa dinamicidade pode ser verificada na operacionalização de jogos matemáticos estimulando o desenvolvimento da linguagem, do pensamento e da concentração dos sujeitos/alunos.

Assim os docentes, sujeitos desta pesquisa, também retrataram como utilizam o GeoGebra apontando resultados atingidos conforme planejamento e objetivos delineados para o ensino de geometria espacial e para outros conteúdos como aponta o professor B:

Ao lecionar o objeto de conhecimento de funções (afim, quadrática, exponencial e logarítmica) nas minhas turmas de $1^{\circ}$ ano do ensino médio, observei que os alunos conseguiam ter uma aprendizagem mais significativa quando eles mesmo exploravam o aplicativo GeoGebra no celular, na construção dos gráficos e no comportamento dessas funções nesses gráficos. Além disso foram gravados vídeos por eles mesmos em grupos e apresentados em sala de aula como forma de seminário. E através dessa experiência foi observei que o resultado foi satisfatório e que superaram minhas expectativas (Professor B).

Já o professor A compara a evolução na aprendizagem dos alunos considerando o período de aulas planejadas sem auxílio de tecnologias e com o auxílio do GeoGebra:

A primeira vantagem foi nos resultados que eu vi através dos resultados com a mesma disciplinas em anos anteriores as notas deram um alavancada com certeza porque eles faziam essa ligação ne de como eles viam no programa, e viam na prova ,isso eu achei bem legal e eu percebi também a criatividade deles com relação as questões porque eles conseguiam visualizar de uma forma que ele não conseguiam visualizar antes com o programa né então achei bem legal isso , mais principalmente os resultados em si, as notas foi o que mais me chamou atenção (Professor A)

$\mathrm{O}$ professor $\mathrm{C}$ parece ir mais além em suas reflexões, sobretudo porque suas experiências em sala de aula já vinham acontecendo desde seu processo de formação docente:

Como eu já entrei na sala de aula para regência antes de concluir a vida acadêmica, então eu me deparei com questões superficiais dentro da escola que me fizeram impulsionar e até repaginar na matemática, para que conseguisse levar o aluno por esse caminho ou trilhar esse caminho de aprendizado, que é o ensino de aprendizagem da matemática e aí um dos pontos principais como metodologia foi o uso de recurso tecnológicos e aí falando de recurso tecnológicos a gente já pode elencar aqui por exemplo o GeoGebra. Ela é uma das ferramentas mais completas, acredito eu, para ensinar a geometria ou a álgebra fazer essa ligação entre a parte algébrica e a parte de desenho geométrico (Professor C).

Em relação ao ensino remoto, contexto no qual a investigação foi desenvolvida, a facilidade em utilizar o GeoGebra para ensinar geometria espacial caracterizou-se pelo fato de que esse software pode ser baixado em forma de aplicativo em smartfones, como relatado pelo professor $\mathrm{B}$, mesmo se utilizando de estratégias para alcançar a todos, rompendo a barreira social de falta de acesso aos recursos digitais que é uma realidade para parte considerável dos alunos: 
Então, para o ensino remoto eu costumo usar o GeoGebra móvel que é aquele aplicativo de celular e ele pode ser usado em qualquer smartfone, basta depois de baixado no celular não necessariamente precisa do uso da internet para poder usar, os alunos podem usar sem o acesso a internet, então eu costumo fazer roteiros de aulas de como a gente vai utilizar daí então os alunos possam fazer suas próprias construções em suas próprias casas e eles podem ir montando suas construções utilizando o GeoGebra no celular, então com isso a gente pode posteriormente discutir sobre essas construções durante as aulas, então dessa forma eu sempre procuro deixar com o que eles façam além do que é dado no roteiro, então dessa forma eles podem explorar as criatividade deles nas construções e aprender a usar de forma autônoma o aplicativo do GeoGebra, mostrando vestígios de criatividades e com um aluno criativo ele vai saber utilizar o GeoGebra da melhor maneira possível, explorando os recursos e trazendo até mesmo novas possibilidades de uso para o professor. (Professor B).

Como relatado pelo entrevistado, o GeoGebra pode ser usado no celular sem a necessidade de internet, o que facilita o acesso a esse software e a aprendizagem dos alunos de todas as classes sociais, porque a suspensão das aulas presenciais em virtude da pandemia da COVID-19, colocou em evidência duas situações presentes nas instituições brasileiras de diferentes níveis: a desigualdade social existente entre os educandos e as lacunas existentes no uso de Tecnologias de Comunicação e Informação - TIC (CRUZ et al., 2020).

\section{Dificuldades e desafios na utilização do software GeoGebra}

O planejamento do ensino visando uma aprendizagem significativa deve segundo Vygotsky (1991 ser articulado numa perspectiva contextual, em que os conteúdos abordados dialoguem com a realidade do sujeito/aluno. Assim faz necessário conhecer a realidade do objeto que se deseja planejar e quais as principais necessidades que precisam ser trabalhadas. Para que o planejador as evidencie faz-se necessário, como argumenta Oliveira (2007), "fazer primeiro um trabalho de sondagem da realidade daquilo que ele pretende planejar, para assim, traçar finalidades, metas ou objetivos daquilo que está mais urgente de se trabalhar"

Nessa perspectiva, constatou-se através da fala da maioria dos docentes a dificuldade de se trabalhar o ensino da Matemática utilizando as TICs especialmente pela questão social dos alunos, em que muitos deles têm dificuldade de acesso à internet, ou mesmo por não possuir um aparelho de celular. Isso fica evidente nos seguintes depoimentos:

Durante uma aula ao usar softwares educacionais observei que nem todos os alunos têm domínio do uso da tecnologia (celular/computador), pois nem todos têm contato com essas tecnologias digitais em seu meio social e familiar. Daí é notório a dificuldade que esses alunos têm na hora de usar tais tecnologias no 
ambiente escolar, logo o professor precisa se dispor a instrui-los no uso dessas ferramentas (Professor C).

Ao trabalhar a Equação do $1^{\circ}$ Grau a partir do Sr. X, aplicativo da Play Store, percebi que o ponto negativo ao usar recursos tecnológicos educacionais foi que alguns alunos por não terem aparelho telefônico não participaram com tanta motivação em relação aos outros que tinha aparelho. Percebendo essa situação agrupei os alunos para minimizar os impactos negativos na aprendizagem de matemática diante desse planejamento da sequência didática (Professor D).

A única parte negativa seria que como nem sempre temos tempo suficiente em sala para trabalhar o conteúdo, seria bom que todos tivessem acesso ao software em casa também como reforço, mas sabemos que nem todos tem esse acesso (Professor A).

Observa-se também, nestes depoimentos, que a falta de equipamentos adequados na escola para utilização dos softwares educacionais, como laboratórios de informática, por exemplo, afeta o planejamento do ensino. Por outro lado, precisa-se de uma formação adequado para os docentes ao lidar com softwares educacionais

Para Ávila et al. (2014) faz-se necessário pensar na formação de professores, principalmente na formação de professores de Matemática, de modo que estes tornem-se capazes de explorar os mundos virtuais como espaços para a promoção de uma aprendizagem mais satisfatória para seus alunos. "O estado e as escolas poderiam incentivar mais o uso com cursos de formação de plataformas e aplicativos realmente utilizáveis e não apenas demonstrativos (Professor A).

Entretanto, olhando para as respostas dos sujeitos, presente no questionário (diagnostico inicial), percebe-se que uma parte significativa dos docentes ainda se mostram bastante reticentes em relação ao uso dos recursos digitais educacionais em sala de aula, alegando despreparo ao uso dos instrumentos tecnológicos no contexto escolar. Outros ainda não se acham capacitados para lidar com os alunos em aulas informatizadas, pois tais atividades exigem habilidades profissionais específicas.

Dessa forma, podemos perceber que as dificuldades e desafios na utilização de softwares educacionais, na sala de aula, sobretudo o GeoGebra relaciona-se com o desejo do professor de tornar a aprendizagem mais significativa, diversificando a apresentação de conceitos na perpectiva da diversificação das possibilidades de investigação ao favorecer características dinâmicas para representações relacionadas com gráficos, geometria espacial e procedimentos algébricos.

\section{PROPOSTA DE ENSINO COM AUXÍLIO DO GEOGEBRA}

Com o auxilio do software GeoGebra, é possivel apresentar os conteúdos de geometria espacial de forma diversificada contribuindo para uma possibilidade 
metodológica pautada pela criatividade tanto de quem ensina quanto de quem aprende, em que as questões elaboradas têm o potencial de auxiliar o percepção geométrica do aluno. Isso fica evidente a partir do depoimento dos professores.

Uma sequencia didática do conteúdo da geometria espacial pode ser realizada através do GeoGebra, uma vez que este software, ao permitir visualizações e construções tridimensionais, permite a construção de objetos para experimentação e exploração de conceitos dentro da Geometria Plana e Espacial, como um recurso dinâmico e interativo.

Os depoimentos dos professores colaboram com o pensamento de Alves e Borges Neto (2012) mostrando que a tecnologia pode afetar o processo de mediação no ensino de determinados tópicos, porém, seu uso de forma complementar enfatiza uma mudança dimensional, com o objetivo de identificar elementos de natureza qualitativa. Assim, a prática de sala de aula com a utilização do GeoGebra pelos participantes desta pesquisa sugere uma proposta de ensino relevante para melhorar a aprendizagem do aluno em geometria espacial, seja por meio do desenvolvimento da percepção e ou da visualização geométrica, podendo ser disseminada a partir dos depoimentos dos professores ao utilizar a tecnologia em foco, rompendo barreiras e obstáculos pré-existentes no processo de compreensão deste tema.

\section{REFERENCIAS}

ABAR, C. A. A. P.; COTIC, N. S. GeoGebra na produção do conhecimento matemático. São Paulo: Iglu, 2014.

ANDRADE, L. N. Geometria espacial com GeoGebra. Revista do Professor de Matemática, São Paulo, n. 87, p. 36-41, $2^{\circ}$ quadrimestre 2015.

BORBA, M. C.; SCUCUGLIA, R. S. R.; GADANIDIS, G.. Fases das tecnologias digitais em Educação Matematica: Sala de aula e internet em movimento. Belo Horizonte: Autêntica Editora, 2016.

BORBA, M. C.; PENTEADO, M. G. Informática e Educação Matemática. Belo Horizonte: Autêntica Editora, 2017.

BRASIL. Ministério da Educação. Base Nacional Comum Curricular. Brasília, 2018.

CRUZ, J.; TAVARES, E.S.; COSTA, M. Aprendizagem significativa no contexto do ensino remoto. Dialogia, São Paulo, n. 36, p. 411-427, set./dez. 2020.

DUVAL, R. Registros de representação semiótica e funcionamento cognitivo do pensamento: Revista Eletrônica de Educação Matemática, v. 7, n. 2, p. 266-297, 2012.

FANTI, E. L. C. Utilizando o software GeoGebra no ensino de certos conteúdos matemáticos. In: Bienal da Sociedade Brasileira de Matemática. Universidade Federal da Paraíba, João Pessoa, 5, 2010, João Pessoa. Anais... João Pessoa: UFPB, 2010, p. 1-16. 
GIRARDO, V., Integrando Geometria e Funções: gráficos dinâmicos. In Revista do Professor de Matemática, São Paulo, n. 79, p. 39-46, 3º quadrimestre 2012.

GRAVINA, M. A. O potencial semiótico do GeoGebra na aprendizagem da Geometria: uma experiência ilustrativa. Vidya, v. 35, p. 237-253, 2015.

GRAVINA, M. A. Geometria Dinâmica: uma nova abordagem para o aprendizado. In: Simpósio Brasileiro de Informática na Educação, 7., 1996, Belo Horizonte, Anais... Belo Horizonte, 1996.

KESNKI, V. M. Tecnologias e ensino presencial a distância - Campinas, SP: Papirus, 2003. - (Série Prática Pedagógica).

KENSKI, V. M. Educação e tecnologias: o novo ritmo da informação. Campinas, SP: Papirus, 2007.

MOREIRA, M.A., Caballero, M.C. e Rodríguez, M.L. (orgs.) (1997). Actas del Encuentro Internacional sobre el Aprendizaje Significativo. Burgos, España. pp. 19-44.

OLIVEIRA, Dalila de Andrade. Gestão Democrática da Educação: Desafios Contemporâneos. $7^{\mathrm{a}}$ edição. Petrópolis, RJ. Editora Vozes, 2007.

PEREIRA, T. L. M. O uso do software GeoGebra em uma escola pública: interações entre alunos e professor em atividades e tarefas de geometria para o ensino fundamental e médio. 2012. Universidade Federal de Juiz de Fora, Juiz de Fora, 2012.

TEIXEIRA, A.C.; BRANDÃO, E. J. R. Software educacional: o difícil começo. RENOTE - Revista Novas Tecnologias na Educação. v. 1, n. 1. 2003.

VYGOTSKY, L.S. Pensamento e Linguagem. São Paulo, Martins Fontes, 1987. 